Ethiopian Journal of Environmental Studies \& Management 9(Suppl. 2): 1022 - 1035, 2016. ISSN:1998-0507 Submitted: August 27, 2016 doi: http://dx.doi.org/10.4314/ejesm.v9i2.8S Accepted:December 19, 2016

\title{
CLIMATE CHANGE AND NEXT GENERATION CELLULAR SYSTEMS
}

\section{*FARUK, N., ${ }^{\text {* BELLO, 0.W., }}{ }^{2,4}$ OLOYEDE, A.A., ${ }^{1}$ OGUNMODIMU, 0. ${ }^{3,6}$ AND} OLAWOYIN, L.A.1,5

${ }^{1}$ Department of Telecommunication Science, University of Ilorin, Ilorin, Nigeria ${ }^{2}$ Department of Information and Communication Science, University of Ilorin, Nigeria

${ }^{3}$ Department of Physics, Lancaster University, LA1 4YW, UK

${ }^{4}$ Nova Information Management School, Universidade Nova de Lisboa, Portugal

${ }^{5}$ Beijing University of Posts and Telecommunications, Beijing 100876, China

${ }^{6}$ National Space Research Development Agency, Abuja

\begin{abstract}
As climate change could affect energy production, it can also undermine telecommunications development which requires increased energy consumption to drive improvement in network penetration, coverage and capacity. Employing secondary data analysis and simulation, this paper presents a study on climate change effect on energy consumption of telecommunication base stations. The impact of climate change on energy consumption was examined by introducing a climate factor, $\chi$, into validated Base Transceivers Stations (BTS) power consumption models. The BTS energy demand was found to increase with increase in temperature due to cooling requirement. The result shows that, with $1^{\circ} \mathrm{C}$ increase in outdoor temperature, heat flow through BTS shelter increases by $6.25 \%$. This increase effect, manifests on cooling system with above $1 \mathrm{~kW}$ power. The result presented shows the importance of taking climate change variables into consideration when planning next generation cellular networks for sustainable deployment.
\end{abstract}

Key Words: Climate change, renewable energy, cellular systems, base stations, mmWave communication, sustainability

\section{Introduction}

Global concern for climate change, is observable in the form of extreme heat waves, rising sea-levels, changes in precipitation resulting in flooding, droughts and intense hurricanes among other natural disasters, has considerably heightened over the years (Hossain et al., 2011). More alarming is its threat to undermine decades of development across different sectors of man's life, which include wireless/cellular telecommunications that is significantly contributing to ICT and global sustainable development. These contributions are based on its ease and speed of deployment, less disruption to the physical environment among other factors.

Cellular networks are more preferred in meeting the increasing demand for data rate which is expected to escalate by eightfold in 2020 (Cisco, 2016). However, improving the network penetration (coverage) and capacity hinges on increased network energy 
consumption. This account for about 15 $\%$ of its running cost in industrialized markets and could be above $50 \%$ in developing economies where the network operators run considerable number of their base stations off grid due to non-availability of power supply (Nokia Network, 2015). This upsurge in energy consumption does not only impact the global climate, but also puts additional burden on the business case of the network service providers, which has a considerable effect on sustainability. Temperature, precipitation, storms-wind-extremeevents; humidity and sea-level rise which are weather variables affected by climate change are identified as having potential impacts on telecommunication (GSA, 2014). It is important to note that energy production could also be affected because hydropower and solar are susceptible to climate change. These impacts could be positive or negative. For example, while an increase in the average temperature could mean more need for cooling which requires energy to achieve, same may reduce the frequency of the need to cope with snow-melt (Horrocks et al., 2010).

Furthermore, millimeter wave (mmWave) communications have been identified as a new paradigm that can offer potential solutions to the anticipated high capacity requirements of next generation cellular networks owing to the large available spectrum in the millimeter wave frequencies. However, at extremely high frequency of about $60 \mathrm{GHz}$, there is a risk of increased attenuation due to rain and oxygen absorption which could range from 15 to $30 \mathrm{~dB} / \mathrm{km}$ (Daniel and Health, 2007). This could manifest with global tilt in climate variables.

The energy demand of base stations increases with high temperature due to cooling requirement. Accordingly, it is noted that climate change might have an impact on continuous heating and cooling processes. The overall energy requirement for temperature control purposes may vary geographically as different geographical locations come with varying climatic conditions. These climatic conditions have varying effect on the energy consumption of BTS which is principally related to the prevalent average temperature in the different locations at different time of the day, month and year. Köppen's climate classification is a widely used climate classification and it is based on the annual and monthly averages of temperature and precipitation (Pidwirny, 2006). Significant percentage of energy consumption is also dependent on other variables such as energy efficient technology, and technological advancement.

\section{Use of Renewable Energy Sources}

Globally, one major change that is advocated as a result of climate change is the transfer from the use of fossil fuel to renewable energy sources. This has led to a huge demand for renewable energy in developed and developing countries alike. According to 2014 global status report, renewable energy contributed about $22 \%$ of the energy generated in 2013 (NREP, 2014). (Munner, 2007) opined that the use of renewable fuel is expected to continue to grow over the coming years despite the fact that non-renewable fuel sources such as coal, oil and gas remains a major source of energy for most countries. This is manifested in the 2015 report by IEA (Ren21, 2015), that renewable energy increased by about $128 \mathrm{GW}$ in 2014 making up over $45 \%$ of new additions to power generation in the same year. An overall increase of $30 \%$ primary energy supply from renewable sources was recorded from 2004 to 2013 and accounted for $19 \%$ of the world's 
final energy consumption in 2013 (Ren21, 2014). Likewise, an increase of $152 \mathrm{GW}$ in total renewable power capacity was reported between 2014 and 2015 (Ren21, 2015). This is an improvement in the 2014 increase by 26 GW.

\section{Changes in Precipitation Patterns}

Precipitation changes as a result of climate change would differ from one region to another. Some would experience more rain while others would become dryer. (Trenberth, 2011) has also shown that the subtropical areas would experience a fall in precipitation while there are uncertainties regarding the faith of the equatorial regions. A change in precipitation can result into more or less vulnerability of power plants such as hydropower plant, nuclear plants among others. Nuclear plants consume about 1200 gallons of water per MW hour for wetting and cooling the towers. Hydro power plant consumes about 4500 gallons of water per MWh and natural gas plant consumes about 100 gallons /MWh (NREP, 2014). A fall in precipitation can lead to water shortfall for hydro power plants because of its sensitivity to the timing and volume of water flow in the dam (Pan et al., 2011). Hydroelectricity accounts for about 20 percent of the global electricity generation in about 150 counties and it being relatively cheap to produce and renewable makes its common in developing countries. A fall in power generated would have an effect on the BTS connected to the national grid.

\section{Temperature and Wind Variability}

The most obvious change as a result of climate change is an increase in temperature leading to global warming. Averagely, the global temperature has increased approximately by $0.8^{\circ} \mathrm{C}$ in the last century (Pan et al., 2011). However, occurrence of storms, prolonged rainfall and natural disasters has been on the increase in some regions in the last decade. This is affecting the availability of sun for solar generation. According to IPCC (NREP, 2014), there is going to be a reduction of up to $20 \%$ in the seasonal solar power radiation based on a simulation projection model carried out for up to the year 2040. On the other side, increase in temperature can also affect the production of fossil fuel and nuclear energy as a result of change in the ambient temperature. Furthermore, the change in the wind variability could affect the citing and availability of wind generated power plants however; there is insufficient research to show the extent of wind variability as a result of climate change.

\section{Climate Change and Millimeter Wave} (mmWave) Communications

The recent exploration of the mmWave frequency spectrum for access and backhaul for the next generation cellular communication is mainly driven by the unprecedented challenges of global bandwidth scarcity created by the yearly proliferation of mobile data traffic worldwide (Rappaport, 2011). The introduction of mmWave technology and carrier aggregation mechanisms into cellular communication systems becomes highly needful in order to adequately support the exponential increase in the predicted mobile traffic volumes. The main challenge of mmWave communications is that there is a risk of increased attenuation due to rain and oxygen absorption which could range from 15 to $30 \mathrm{~dB} / \mathrm{km}$ and higher (Zhao and $\mathrm{Li}$, 2011). Moreover, satellite is seen as prime option for small cell backhaul for next generation systems particularly in no hot spot areas, typically rural communities where there is the predominant demand for voice service. It could also serve as backhaul for small cells in ships and airplanes. However, 
coronal mass ejections (CMEs) events could occur alone or in association with solar flare. When these solar events happen their impact could be detrimental to satellites and global communications systems.

Although, research efforts, have been carried out in (Lubritto, 2011; Yu, et al., 2015), on the effects of some of the climate change variables on energy consumption and production. However, it is not very clear to what extent for example, how $1^{\circ} \mathrm{C}$ increase in climate temperature will affect the energy consumption. Therefore, based on extant literature survey, examination of secondary data sources, simulation and modeling, this paper presents a study on the effect of climate change on energy consumption of telecommunication base stations, global energy production and mmWave communication.

\section{Methodology}

In this paper, we consider a telecommunication macro base station (BTS) consisting of three main segments: the transmission equipment (TE), cooling and auxilliary equipment (AE). The TE includes the power amplifiers (PA), transcivers (TX), digital signal processing (DSP) and rectifiers; cooling include the air conditionning systems or the fan and the $\mathrm{AE}$ are basically the lightining bulbs and security alarms. In addition, backhaling such as the point-to-point or point-tomulti-point micorwave antennas may be present at the BTS sites where fiber cables are not avaialble. Fig 1 shows the block digaram of a typical BTS equipment considered. Among these components, the AC and power amplifiers conribute the larger share of the power consumption. High efficient power amplifiers has been developed and currently in deployment, however, high operating back off and heat dissipation gives rise to non linearity effect which leads to poor power effiency $\mu_{P A}$ and increased power consumption (Auer et al., 2011).

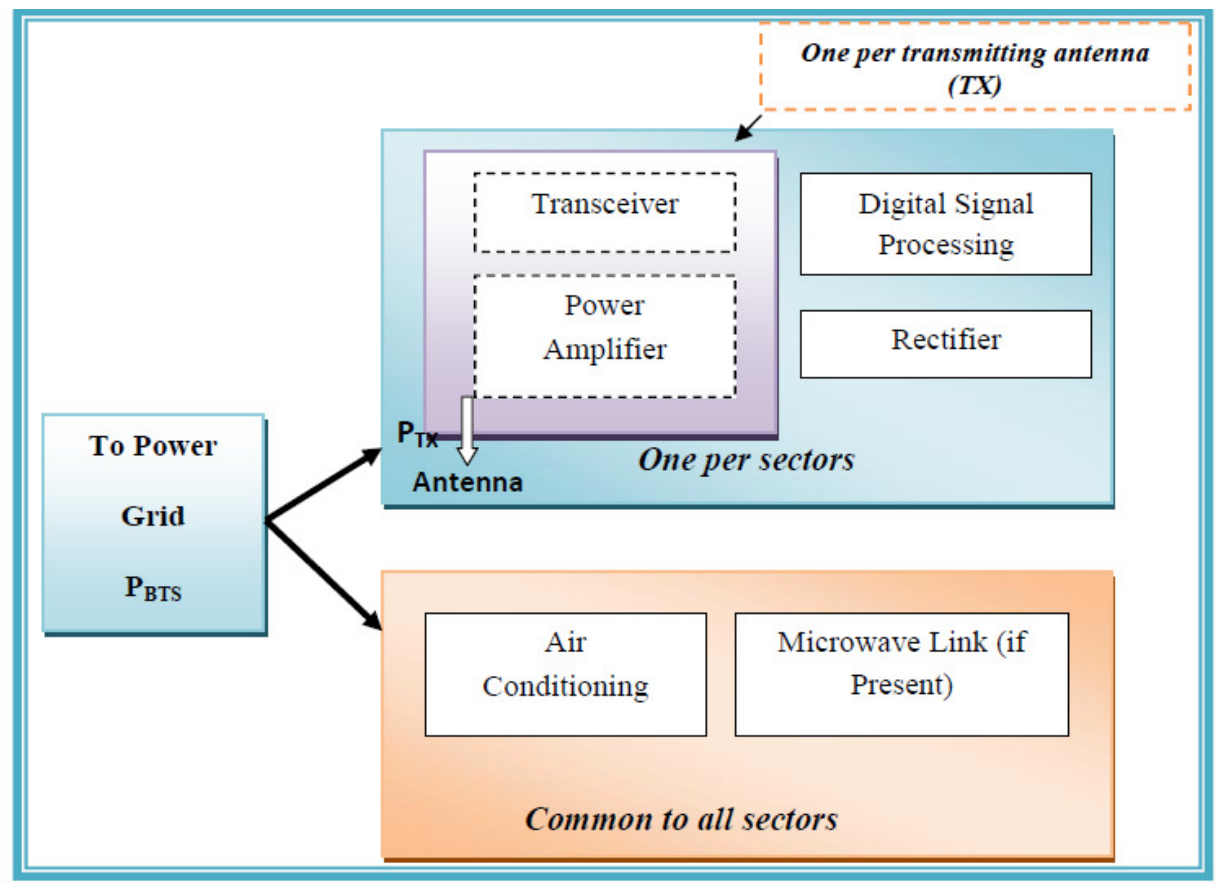

Figure 1: Block diagram of base transceiver station (BTS) 
The power consumption of a PA is defined by: $P_{P A}=P_{o u t} / \mu_{P A}\left(1-\delta_{\text {feed }}\right)$. Depending on the climatic condition, system topologies and location, active cooling systems are ususally used to regulate the internal temperature of the shelter or room where the radio Table 1: Base Station Types

\begin{tabular}{|c|c|c|c|c|}
\hline \multirow[t]{2}{*}{$\begin{array}{l}\text { Base Station BS } \\
\text { Type }\end{array}$} & \multirow[t]{2}{*}{ Coverage } & \multicolumn{2}{|c|}{$\begin{array}{l}\text { Radiated } \\
\text { Power (W) }\end{array}$} & \multirow[t]{2}{*}{$\begin{array}{l}\text { Power } \\
\text { Consumption (W) }\end{array}$} \\
\hline & & Indoor & Outdoor & \\
\hline Macro & $<35 \mathrm{~km}$ & - & $5-40$ & $1000-5000$ \\
\hline Micro & $<2 \mathrm{~km}$ & - & $0.5-2$ & $100-300$ \\
\hline Pico & $<200 \mathrm{~m}$ & 0.1 & $0.25-2$ & $9-15$ \\
\hline Femto & $10-15 m$ & $<0.1$ & - & $6-14$ \\
\hline
\end{tabular}

\section{Base Station Power Consumption Model}

Power consumption models are used to determine the power consumption of the BTS. To that end, we utilize some simple and validated power consumption models presented by (Auer, 2011; Deruynk, 2011; Faruk et al., 2013). For our simulation, we assumed the power consumption of rectifier (s) to be constant over time. The internal temperature of the base station shelter is assumed to be $25^{\circ} \mathrm{C}$.

$$
P^{B T S}(f)=P_{E}\left(f, T_{i n}(t)\right)+P_{\text {Cool }}\left(f, T_{\text {out }}(t)\right)+\sum_{i=1}^{n} P_{A u x, i}
$$

and

$$
P_{E}\left[f, T_{i n}(t)\right]=n_{\text {sector }} \times\left(f \times\left(n_{T X} \times\left(P_{P A}+P_{T R X / R F}\right)+P_{D S P}\right)+P_{r e c}\right)+\sum_{i=1}^{m} P_{i}^{\text {link }}
$$

where $n_{\text {sector }}$ is the number of sectors, $f \quad$ the load factor representing the number of active users, $n_{T X}$ the number of transmitting antennas, $P_{P A}, P_{R F}, \quad P_{D S P}, \quad P_{r e c}, \sum_{i=1}^{m} P_{i}^{\text {link }}$ and $P_{\text {cool }}$ are the power consumption (in watt) of PA, the transceiver, the DSP, rectifier, the microwave backhaul link and the cooling. We analyzed the power consumption by modeling the whole BTS power consumption using the simulation parameters stated in Table 2.

\section{Cooling Load Model and Climate Factor}

Indoor temperature $\left(T_{\text {in }}\right)$ between 0$30^{\circ} \mathrm{C}$ do not have significant impact on the transmission equipment's power 
consumption ( $\mathrm{Yu}$ et al., 2015), although, it could affect the battery life of the backup storage. The effect could however manifest when the $T_{\text {in }}$ exceeds $40{ }^{\circ} \mathrm{C}$ due to heat dissipated by the transmission equipment. The air conditioning is then used to maintain the indoor temperature of the BTS shelter below $30^{\circ} \mathrm{C}$. Increase in outdoor temperature $\left(T_{\text {out }}\right)$ on the other hand causes rise in power consumption of AC (Yu et al., 2015), this implies that $T_{\text {out }}$ is the main contributing factor to AC's power consumption and ultimately the overall BTS. Therefore, to maintain a required $T_{\text {in }}$, the $\mathrm{AC}$ will have to remove heat generated outdoor. The cooling load of the AC includes (Spagnuolo et al., 2015; Wang et al., 2011).

\section{The Transmission Load}

This is responsible for the heat gain due to temperature difference across the BTS shelter and is given by:

$$
\phi_{T}=A_{S} \times U \times\left(T_{\text {out }}-T_{\text {in }}\right)
$$

\section{Infiltration Load}

This is the heat gain due to inflow of outdoor air to the shelter though cracks or any air leakage and is given by:

$\phi_{I}=q_{v} c_{p} \rho \times\left(T_{\text {out }}-T_{\text {in }}\right)$

\section{Latent Load}

This is the heat gain due to change in humidity between indoor and outdoor and is computed using equation (5):

$$
\varphi_{L}=h q_{v} \rho \times\left(W_{\text {out }}-W_{\text {in }}\right)
$$

\section{Solar Load}

This is the heat gain due to solar radiation transmitted and absorbed by the shelter and is computed using equation (6):

$$
\phi=G A \times(1-\lambda)
$$

\section{Internal Load}

This is the heat gain due to heat dissipation by the transmission equipment and is computed using equation (7):

$$
\phi_{\text {Int }}=G_{\text {light }} F(t)+c_{o} A_{S}
$$

where:

$A_{s}, U, \mathrm{q}_{\mathrm{v}}, \mathrm{c}_{\mathrm{p}}, \rho, \mathrm{h}, \mathrm{w}_{\text {out }}, \mathrm{W}_{\text {in }}, \mathrm{G}, \mathrm{A}, \lambda, \mathrm{G}_{\text {light }}$, $\mathrm{F}(\mathrm{t})$ and $\mathrm{c}_{\mathrm{o}}$ are the area of the shelter, transmittance of the shelter wall, volumetric air flow rate, specific heat capacity of air, air density, change in enthalpy between indoor and outdoor, outdoor specific humidity, indoor specific humidity, solar power that arrives on one $m^{2}$ of soil, actual area affected by solar radiation, reflectivity of the external wall, total light wattage, lighting use factor and coefficient respectively.

Therefore, using equations (3)-(7), the total cooling load $(\mathrm{W})$ is obtained as;

$\varphi_{\text {cool }}(t)=A_{S} \times U \times\left(T_{\text {out }}-T_{\text {in }}\right)+q_{v} c_{p} \rho \times\left(T_{\text {out }}-T_{\text {in }}\right)+h q_{v} \rho \times\left(W_{\text {out }}-W_{\text {in }}\right)+G A \times(1-\lambda)+G_{\text {light }} F(t)+c_{o} A_{S}$

Assuming the infiltration, internal, solar and latent loads to be constant, $\mathrm{K}$ then, equation (8) can be written as;

$$
\phi_{\text {cool }}(t)=A_{S} \times U \times\left(T_{\text {out }}-T_{\text {in }}\right)+\mathrm{K}
$$


To simplify this further, we assume the indoor temperature is uniform through the entire shelter and the external temperature is homogeneous whereby, effects due to wind is neglected. Due to the increase in carbon dioxide and other heat trapping gases as the results of human activities, research outcomes has shown that the world would likely continue to get warmer and the increase in average temperature could be between 1.1 to $5.4{ }^{\circ} \mathrm{C}$ and higher (David, 2016). Therefore, this increase in temperature is expected to affect the overall power consumption of the BTS. We model this effect by introducing a climate factor, $\chi$, which represent the increase in average outdoor temperature due to global climate change. Therefore, equation (9) can be written as:

$$
\phi_{\text {cool }}(t)=A_{S} \times U \times(\delta T+\chi)+\mathrm{K}
$$

Where $\delta T$ is the current difference between the indoor and outdoor temperature.

\section{Simulation Parameters}

This study considered 3-sectors LTE BTS with $10 \mathrm{MHz}$ bandwidth and $2 \times 2$ MIMO systems. We considered different PA efficiencies (PAE) value for the BTS of $38.8 \%, 31.1 \%$ and $12.8 \%$. Feeder loss factor of 0.5 and BTS transmitter power is $20 \mathrm{~W}$. We also assumed that the power consumption of these auxiliary equipment is negligible compared to the transmission equipment power. Table 2 provides the simulation parameters and power consumption information for each BTS component used.

Table 2 Simulation Parameters

\begin{tabular}{ll}
\hline Component & Value \\
\hline Area of the shelter $\left(\mathrm{A}_{\mathrm{s}}\right)$ & $30 \mathrm{~m}^{2}$ \\
Reflectivity $\left(\mathrm{A}_{\mathrm{s}}\right)$ & 0.7975 \\
Area of AC window & $0.1 \mathrm{~m}^{2}$ \\
Indoor Temperature $\left(T_{\text {in }}\right)$ & $25^{\circ} \mathrm{C}$ \\
Transmittance $(\mathrm{U})$ & $0.7 \mathrm{~W} /\left(\mathrm{m}^{2} \mathrm{~K}\right)$ \\
Digital signal processing & $100 \mathrm{~W}$ \\
Power amplifier & $103.09 \mathrm{~W}(38.8 \%$ eff $)$ \\
Transceiver $(\mathrm{RF})$ & $100 \mathrm{~W}$ \\
Rectifier & $100 \mathrm{~W}$ \\
Air conditioning & Class A $(2500 \mathrm{~W})$, Class B $(1170 \mathrm{~W})$, \\
& Class C $(225 \mathrm{~W})$ \\
Backhaul & $60 \mathrm{~W}$ \\
\hline
\end{tabular}

\section{Results and Discussion}

The results show that load dependent power consumption for the BTS obtained with the highest at peak load is $1.89 \mathrm{~kW}$ using highly efficient power amplifier of $38.8 \%$ efficiency without any active cooling. This type of scenario is favored in regions with continental or polar climates where the average outdoor temperature is usually a sub-zero temperature and there is no need for active cooling systems. However, in tropical and dry climate regions, active cooling is needed to maintain the indoor temperature below $30^{\circ} \mathrm{C}$, as such, the BTS power increased to $2.12 \mathrm{~kW}, 3.06 \mathrm{~kW}$ and $4.39 \mathrm{~kW}$ when class $\mathrm{C}, \mathrm{B}$ and $\mathrm{A}$ active cooling systems are used on the site respectively, as shown in Fig 2. These values are within the values obtained in various literatures obtained in Table 3 . 
We also investigated the impact of power amplifier efficiency on the overall power consumption of the BTS. It was discovered that the active cooling system have significant impact on the power consumed when compared with the amplifier. Enormous energy could be saved by deploying much smaller base stations that would require less cooling than striving for highly efficient amplifiers.

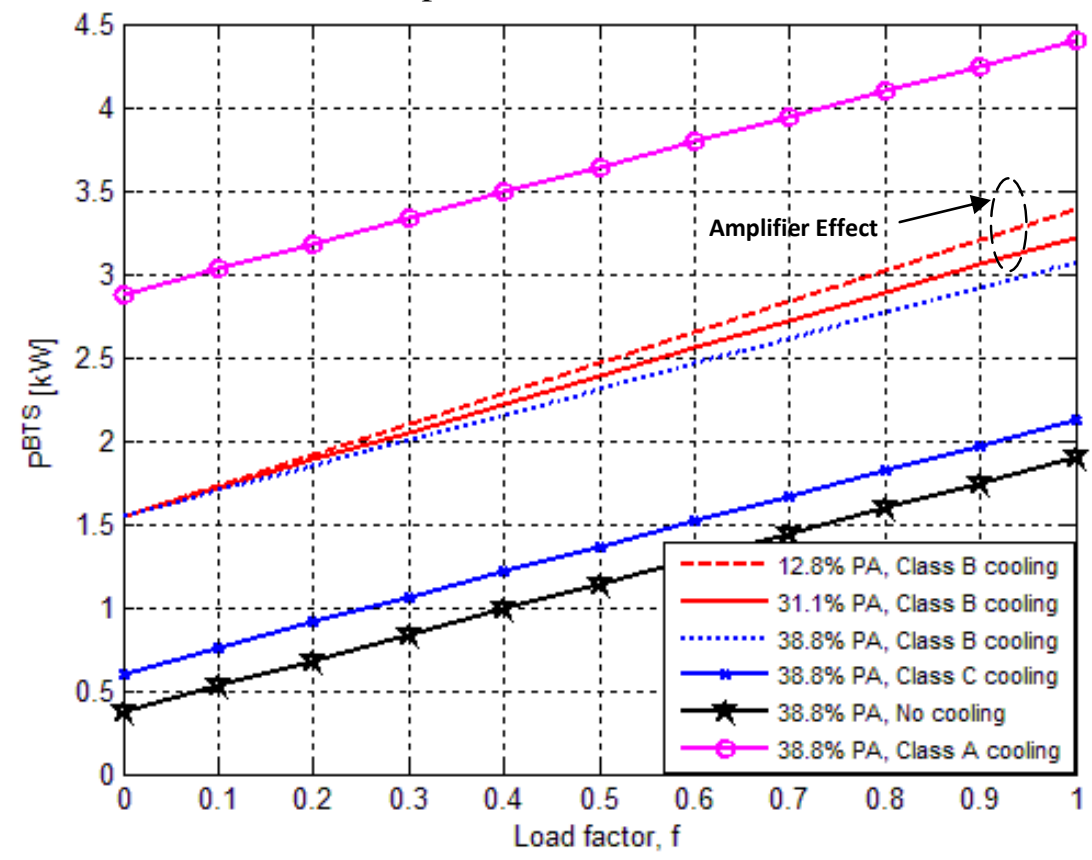

Figure 2: Power consumption of base station as a function of power amplifier efficiency and air conditioning

Table 3: Power Consumption range for Macro base stations

\begin{tabular}{|c|c|c|}
\hline Publications & Power (W) & Comments \\
\hline Auer et al. (2011) & $964.9-1350$ & $\begin{array}{l}2 \mathrm{X} 210 \mathrm{MHz} \text { MIMO, } 3 \text { sector BTS with PAE of } \\
38.8 \% \text { and } 31.1 \% \text {. }\end{array}$ \\
\hline $\begin{array}{l}\text { Spagnuolo et al. } \\
(2015)\end{array}$ & $1700-4900$ & $\begin{array}{l}\text { Measured hourly average power range based on six } \\
\text { MBS in Central Italy. }\end{array}$ \\
\hline $\begin{array}{l}\text { Deruyck et al. } \\
\text { (2011) }\end{array}$ & 1672.6 & $\begin{array}{l}\text { 1TRX, } 3 \text { sector BTS with } 12.8 \% \text { PAE and } 225 \mathrm{~W} \\
\text { active cooling }\end{array}$ \\
\hline Faruk et al. (2013) & $5760-8580$ & $\begin{array}{l}\text { Measured BTS site for MTN network in Nigeria. } \\
\text { Site configurations including: 2G 9TRX } \\
\text { 900BAND, 36TRX 1800BAND and 3G network }\end{array}$ \\
\hline Lubritto et al. (2011) & $3000-4640$ & $\begin{array}{l}\text { Measured BTS site for Vodafone, H3G, Telecom } \\
\text { and Wind networks in South, Center and North } \\
\text { Italy. }\end{array}$ \\
\hline
\end{tabular}

The impact of thermal transmittance and change in outdoor temperatures on the transmission load was also investigated as presented in Fig 3. The thermal transmitter, $U$, indicates the rate of heat flow through the BTS shelter as a function of change in outdoor temperature. Higher 
transmittance indicates poor insulation. Typical examples of materials are clay bricks, concrete block and glass with $U$ values of $0.7 \mathrm{~W} / \mathrm{m}^{2}, 1.1 \mathrm{~W} / \mathrm{m}^{2}$ and 5.7 $\mathrm{W} / \mathrm{m}^{2}$ respectively. Indoor temperature of $25^{\circ} \mathrm{C}$ was maintained, Fig 3 shows that the heat flow into the shelter increases with increase in change in temperature and this varies as a function of the material used for the shelter. In polar region where the outdoor temperature is $-25^{\circ} \mathrm{C}$, the heat flow is $0 \mathrm{~W}$, while for tropical dry climate of $40^{\circ} \mathrm{C}$, the $\mathrm{Q}_{\mathrm{T}}$ is $315 \mathrm{~W}$. At $1{ }^{\circ} \mathrm{C}$ increase in outdoor temperature, the resultant, $\delta T=16{ }^{\circ} \mathrm{C}$ and the heat flow through the shelter increases by $6.25 \%$ which subsequently demand for more cooling.

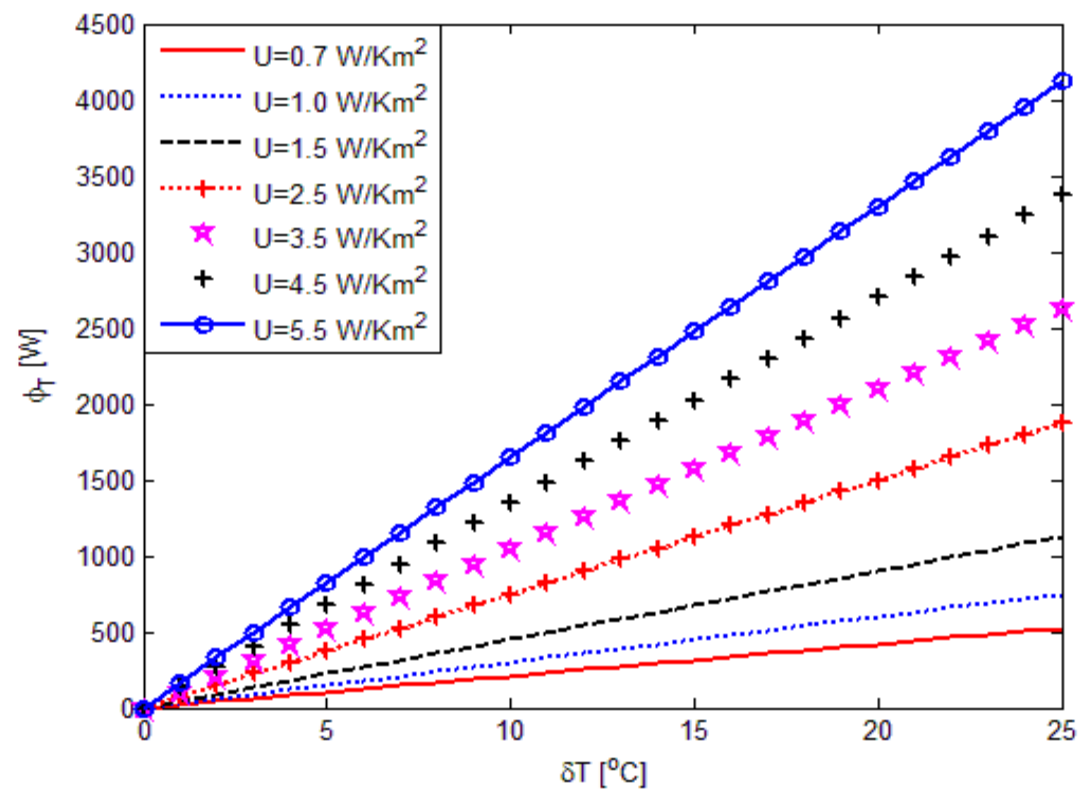

Figure 3: Heat Flux as a function of change in ambient and outside temperatures and Thermal transmittance.

We examined how the thermal transmitter $U$, and the change in temperature $\delta T$ impact on the overall power consumption of the BTS as shown in Fig 4. In this scenario, we assume BTS shelter with $0.7 \mathrm{~W} / \mathrm{m}^{2}$ transmittance (Spagnuolo et al. 2015), surprisingly; the climate factor $(x)$ does not have significant effect on low active cooling systems such as $225 \mathrm{~W}$ ACs. The effect could be noticeable on high class cooling system where the AC consume above $1 \mathrm{~kW}$ of power. However, this is expected to manifest even on low cooling systems when poor insulators are used for the shelter (i.e. $\mathrm{U}>1 \mathrm{~W} / \mathrm{m}^{2}$ ). 


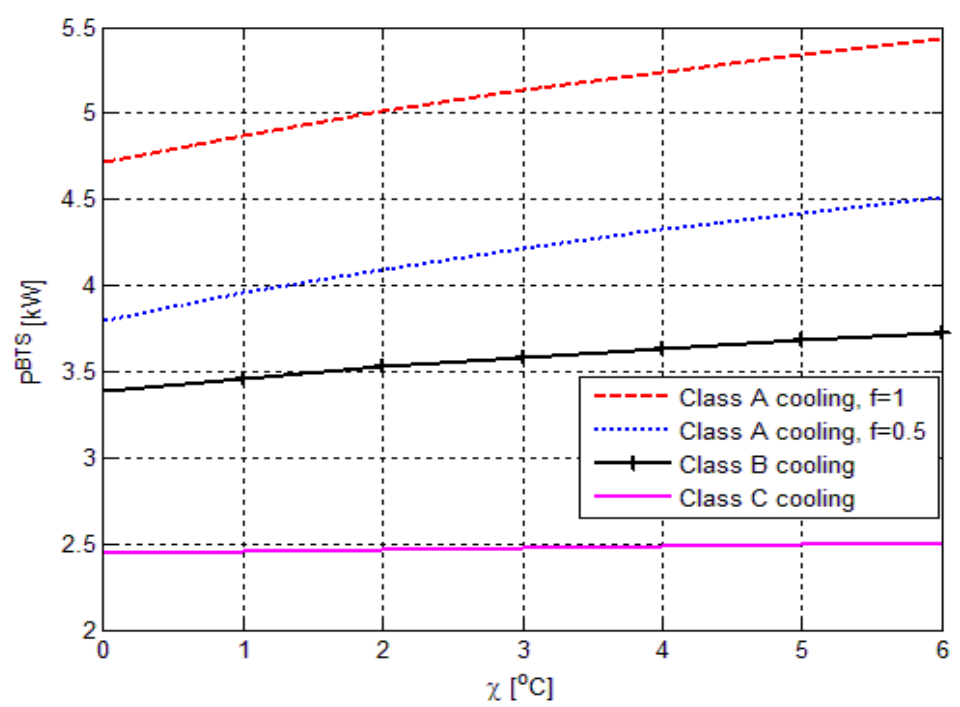

Figure 4: Power consumption of 2X2, 3 sector MIMO BTS as a function of climate factor $(x)$ and the AC cooling class.

Figures 5 and 6 show the effects of atmospheric absorption and rain on mmWave frequencies. In Fig 5, frequencies 57-64 GHz, 164-200 GHz, 320-330 GHz and 370$390 \mathrm{GHz}$ bands are more susceptible to severe oxygen absorption and water vapor absorption.

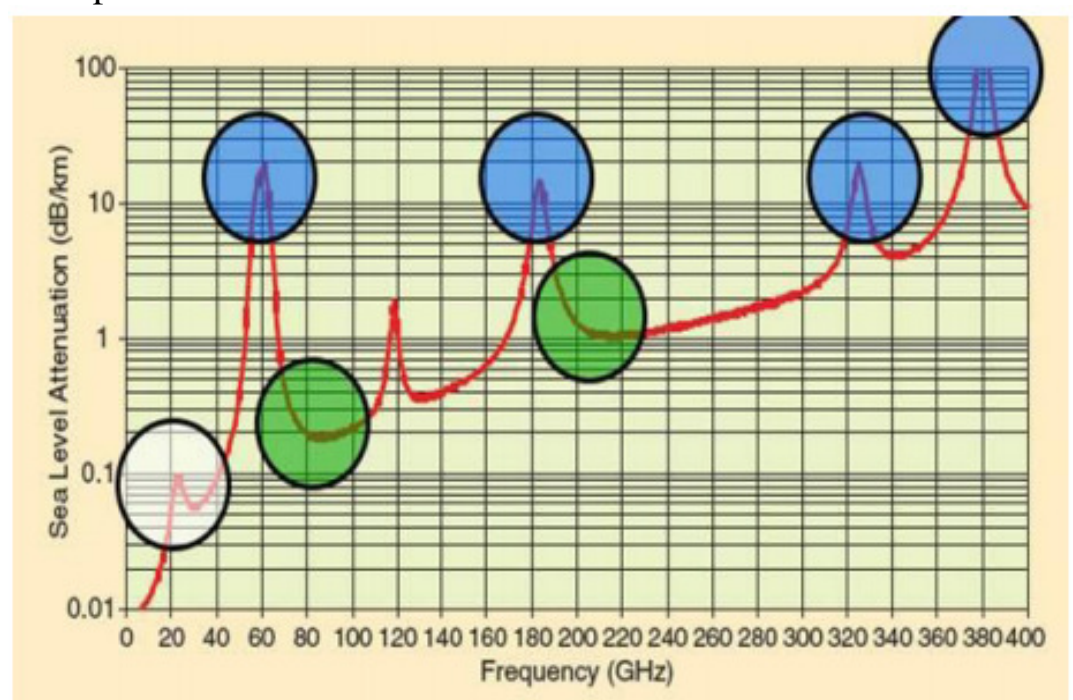

Figure 5: Atmospheric Absorption across mmWave Frequencies in $\mathrm{dB} / \mathrm{km}$ (Rappaport, 2011). 


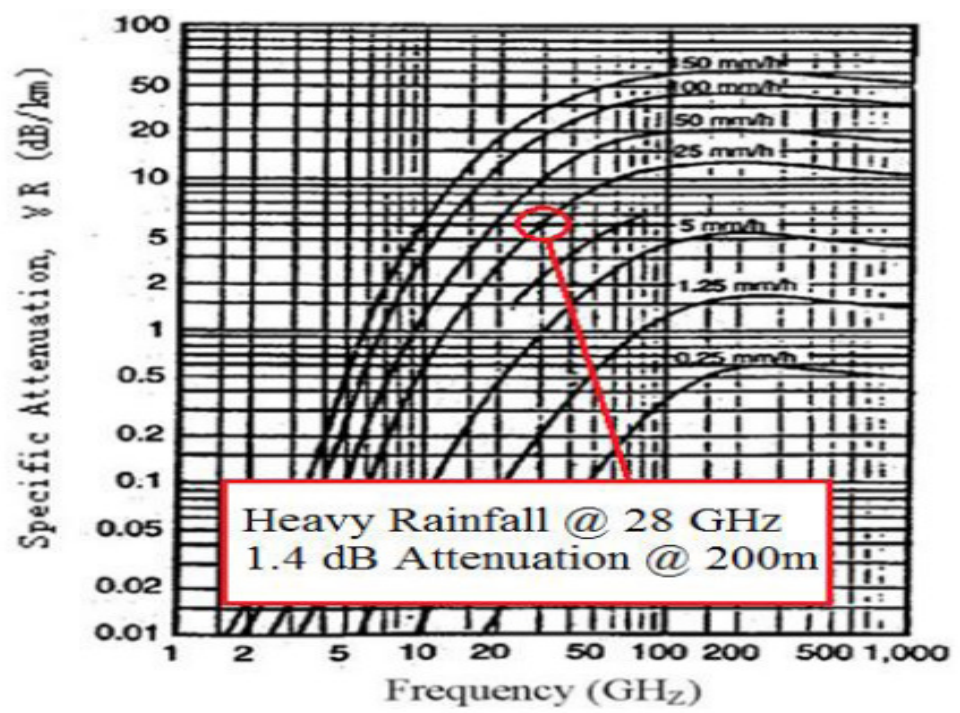

Figure 6: Rain Attenuation in $\mathrm{dB} / \mathrm{km}$ across Frequency at Various Rainfall Rates (Zhao and Li, 2011).

We examined the occurrence frequency of CMEs during solar cycle 23 , sunspot number and the solar radio flux are obtained from the world data center of the National Centers for Environmental Information (NOAA) while CME occurrence is from (Richardson and Cane, 2010). The occurrence frequencies of these events were plotted per year during solar cycle 23 (1996-2009) as shown in Fig.7. It will be observed that the frequency of occurrence is symmetric with the occurrence of sunspot (SSN) and solar

radio flux (F.10). Solar radio flux also correlates well with a number of ultraviolet (UV) and visible solar irradiance records. Many Ultra-Violet emissions that affect the stratosphere and ozone also correlate with the F10.7 index. From the perspective of solar disturbances such as CMEs the frequency of occurrence as in Fig 7 serve as a guide in knowing when to expect the influence of extraterrestrial disruptions to satellite when satellites are deployed as prime option for small cell backhaul.

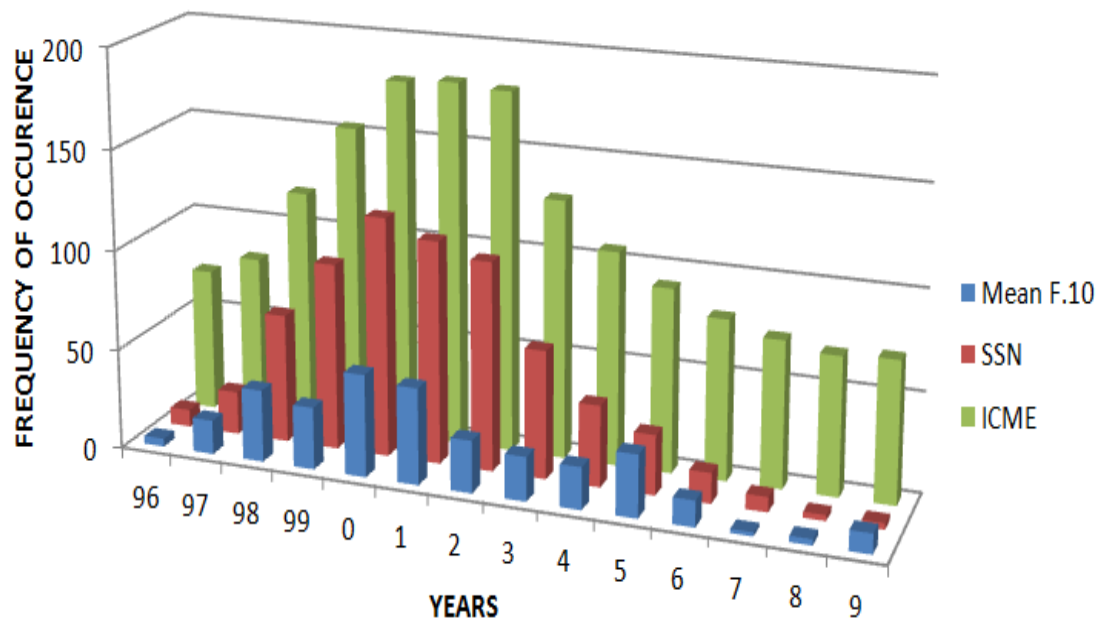

Figure 7: Symmetric Distribution of interplanetary coronal mass ejection (ICME) with sunspot number (SSN) and Mean 10.7cm radio Flux during solar cycle 23 (1996-2009). 


\section{Conclusions}

This research establishes the effect of climate change variables on energy production and energy consumption of telecommunication base stations. The impact of climate change on energy production was found to vary from one country to the other. This also depends on the level of development, the main type of energy generation mechanism and the mitigation and adaptation measure that are in place. In terms of energy consumption, energy demand of base stations was found to increase with increase in temperature due to cooling requirement. Enormous energy could be saved by deploying much smaller base stations that would require less cooling than striving for highly efficient amplifiers.

This paper shows that with $1{ }^{\circ} \mathrm{C}$ increase in outdoor temperature, the resultant heat flow through the BTS shelter increases by $6.25 \%$ which subsequently demand for more cooling. The effect of this increase could be noticeable on high class cooling system where the AC consume above $1 \mathrm{~kW}$ of power. However, with low cooling systems $(<1 \mathrm{~kW})$, more heat will dissipate when poor insulators are used for the shelter (i.e. $\mathrm{U}>1 \mathrm{~W} / \mathrm{m}^{2}$ ). Therefore, in order to minimize excessive energy waste from conditioning, the BTS shelters should be designed with good insulation and material with low thermal conductivity. The research shows the importance of taking climate change variables into consideration when planning next generation cellular networks for sustainable development.

\section{Acknowledgment}

In this work, we acknowledge the Ionospheric propagation laboratory at the Lancaster University, UK for access to satellite data link.

\section{References}

Auer, G., Giannini, V., Desset, C., Godor, I., Skillermark, P., Olsson, M., Imran, M.A., Sabella, D., Gonzalez, M. J., Blume, O. and Fehske, A. (2011). How much energy is needed to run a wireless network? IEEE Wireless Comm., 18(5): 40-49.

Cisco. (2016). Cisco Visual Networking Index: Forecast and Methodology, 2015-2020. White Paper. Accessed 12/06/2016 from: http://www.cisco.com/c/en/us/sol utions/collateral/serviceprovider/visual-networking-indexvni/complete-white-paper-c11481360.pdf

Daniels, R.C. and Heath, R.W. (2007). $60 \mathrm{GHz}$ wireless communications: Emerging requirements and design recommendations. IEEE Veh. Tech. Mag., 2(3): 41-50.

David Herring (2012). Climate Change: Global Temperature Projections. National Oceanic and Atmospheric Administration, USA, https://www.climate.gov/newsfeatures/understandingclimate/climate-change-globaltemperature-projections

Deruyck, M., Emmeric, T., Wout, J. and Luc, M. (2011). Modelling and optimization of power consumption in wireless access network.

Computer Communications, Elsevier, 43(2): 2036-2046,

Faruk, N., Ayeni, A.A., Muhammad, M.Y., Olawoyin, L.A., Abdulkarim, A., Agbakoba, J. and Olufemi, M.O. (2013). Techniques for minimizing power 
consumption of base transceiver station in mobile cellular systems. International Journal of Sustainability, 2(1): 1-11.

GSA (2014). Climate Risks Study for Telecommunications and Data Center Services. REPORT PREPARED FOR THE GENERAL SERVICES ADMIN. By Riverside Technology, inc. and Acclimatize. Copyright (C2014 Riverside Technology, inc.

GSMA (2013). Powering Telecoms: West Africa Market Analysis Sizing the Potential for Green Telecoms in Nigeria and Ghana. Available on http://www.gsma.com/mobileford evelopment/wpcontent/uploads/2015/01/140617GSMA-report-draft-vF-KRv7.pdf.

Horrocks, L., Beckford, J., Hodgson, N., Downing, C., Davey, R. and O’Sullivan, A. (2014). Adapting the ICT Sector to the Impacts of Climate Change, Final Report, Defra contract number RMP5604. London: Defra from https://www.gov.uk/government/u ploads/system/uploads/attachment _data/file/183486/infrastructureae a-full.pd

Hossain, E., Bhargava, V.K. and Fettweis, G.P. (2012). Green Radio Communication Networks, Cambridge press

International Energy Agency Report (2015). Energy and Climate change Found at https://www.iea.org/publications/f reepublications/publication/WEO 2015SpecialReportonEnergyandC limateChange.pdf accessed on 20/06/2016

Lubritto, C., Petraglia, A., Vetromile, C., Curcuruto, C., Logorelli, M.,
Marsico, G. and D'Onofrio, A. (2011). Energy and environmental aspects of mobile communication systems, Energy, 36(2): 11091114.

Muhammad, A. and Muneer, T. (2007). Energy supply, its demand and security issues for developed and emerging economies. Renewable and Sustainable Energy Reviews, 1388-1413.

NREP (Network, Renewable Energy Policy) (1999). Renewables 2014 Global Status Report. Renewable Energy Policy Project. Renewable Energy Policy Outside the US.

Nokia Networks (2014). Technology Vision 2020 Flatten Network Energy Consumption. White Paper. Accessed on 10/05/2016 from;

http://networks.nokia.com/sites/de fault/files/document/technology_v ision_2020_energy_consumption white_paper.pdf.

Pan, Z., Segal, M., Arritt, R.W., Takle, E.S. (2004). On the potential change in solar radiation over the US due to increases of atmospheric greenhouse gases. Renewable Energy, 29(11): 1923-1928.

Pidwirny, M. (2016). Climate Classification and Climatic Regions of the World. Fundamentals of Physical Geography, $\quad 2^{\text {nd }} \quad$ Edition. http://www.physicalgeography.net /fundamentals/7v.html

Rappaport, T.S., Murdock, J.N. and Gutierrez, F. (2011). State of the Art in $60 \mathrm{GHz}$ Integrated Circuits \& Systems for Wireless Communications. Proc. IEEE, 99(8): 1390-1436.

Richardson, I.G. and Cane, H.V. (2010). Near-Earth Interplanetary 
coronal mass ejections during solar cycle 23 (1996-2009): Catalogue and summary of properties, Solar Physics, 264(1): 189-237.

REN21 (2015). THE FIRST DECADE: 10 YEARS OF RENEWABLE ENERGY PROGRESS. Accessed $19 / 6 / 2016$ from http://www.ren21.net/Portals/0/do cuments/activities/Topical\%20Re ports/REN21_10yr.pdf

REN21 (2014). Renewables 2014 Global Status Report. From http://www.ren21.net/Portals/0/do cuments/Resources/GSR/2014/GS R2014_full\%20report_low\%20res .pdf

Spagnuolo, A., Petraglia, A., Vetromile, C., Formosi, R. and Lubritto, C. (2015). Heat flows and energetic behavior of a telecommunication radio base station. Energy, 89: 7583.

Spagnuolo, A., Petraglia, A., Vetromile, C., Formosi, R. and Lubritto, C.
(2015). Monitoring and optimization of energy consumption of base transceiver stations", Energy 81, 286-293.

Trenberth, K.E. (2011). Changes in precipitation with climate change. Climate Research, 47(2): 123-138

Wang, N., Zhang, J. and Xia, X. (2011). Energy consumption of air conditioners at different temperature set points. AFRICON, Livingstone, 1-6.

$\mathrm{Yu}$, M., Xiong, A., Yu, P. and Li, W. (2015). Power consumption modeling of base stations based on dynamic factors. Network Operations and Management Symposium, 538-541.

Zhao, Q. and Li, J. (2016). Rain attenuation in millimeter wave ranges. In Proc. IEEE Int. Symp. Antennas, Propag. EM Theory, 14 